\title{
LINGUISTICS IN FORENSIC LINGUISTIC EXPERTISE (METHOD AND TRUTH) ${ }^{1}$
}

\author{
Anatoliy N. Baranov \\ Russian Language Institute RAS (Vinogradov Institute), Moscow, Russian Federation
}

\begin{abstract}
The paper considers forensic linguistic expertise as a part of applied linguistics that supplies judicial practice with special knowledge - linguistic one. Forensic linguistic expertise is a specific genre of a document and at the same time a result of linguistic research, intended for implementation of linguistic knowledge into other spheres. In this case linguistic theory position might get weakened, as a balance between judicial and linguistic aspects of scientific research might be disturbed. Due to some ignorance to linguistic nature of an expertise activity, justification of methods and techniques of analysis might seem insufficient, unclear and misleading. The problem of research methods is of greater importance in humanitarian sciences, because verification of results, objectification of an intuition of the researcher concerning language matter, psychology of human being or social phenomena are insufficient in this field of scientific investigation.

In forensic expertise verification of results is prerequisite of this type of discourse, defined by the law. In the paper appropriateness of methods are under consideration, which are often mentioned in forensic linguistic expertise as an instrument of data analysis. Such methods as analysis and synthesis, or analysis through synthesis are too general for linguistic research. In another group unclear and undefined methods are included. The case of this kind is conceptual analysis, which every scientist understands in its own way. The term pragmatic analysis has wide extensional from stylistic characteristic of words to social status of participants in a dialogue. Some methods of analysis are understood in a wrong way, i.e. content-analysis, component analysis.

It is shown, that the main method of scientific research that is used by every expert in its work is synonymic transformations. This idea goes back to R. Jacobson, who proposed that a work of linguist consists in rewriting of object text with means of metalanguage into another text. The last one has characteristics which are important for the research: explicitness of meaning, classification of syntactic structures, explication of argument structure etc. Dictionary analysis, summarization, speech act consequences (in term of illocutionary force) reference analysis are just different kinds of synonymic transformations.

Key words: applied linguistics, forensic linguistic expertise, research method, dictionary analysis, synonymic transformation, explication, reference analysis, speech act theory.

Citation. Baranov A.N. Linguistics in Forensic Linguistic Expertise (Method and Truth). Vestnik Volgogradskogo gosudarstvennogo universiteta. Seriya 2, Yazykoznanie [Science Journal of Volgograd State University. Linguistics], 2017, vol. 16, no. 2, pp. 18-27. (in Russian). DOI: https://doi.org/10.15688/jvolsu2.2017.2.2.

УДК $81 ’ 33$

Дата поступления статьи: 10.04.2017

ББК 81.1 Дата принятия статьи: 15.05.2017
\end{abstract}

\section{ЛИНГВИСТИКА В ЛИНГВИСТИЧЕСКОЙ ЭКСПЕРТИЗЕ (МЕТОД И ИСТИНА) ${ }^{1}$}

\section{Анатолий Николаевич Баранов}

Институт русского языка им. В.В. Виноградова РАН, г. Москва, Российская Федерация

Аннотация. Статья посвящена лингвистической экспертизе как разделу прикладной лингвистики, решающей практические задачи, поставленные юридической практикой, и как специальным образом оформленному результату исследования языковых данных для использования его за пределами лингвистики. При таком использовании часто утрачивается контроль теории над практикой применения лингвистических зна- 
ний, нарушается баланс между юридическим и лингвистическим аспектами исследования, игнорируется собственно лингвистический характер знаний экспертов. В первую очередь это сказывается на качестве обоснования системы методов и приемов проведения экспертизы. Проблема методов изучения (их объективности, воспроизводимости, верифицируемости) является сложной для гуманитарных исследований в целом, но для экспертной практики принципиально важной, поскольку определяет научный уровень лингвистических исследований, степень их доказательности. В статье обсуждается вопрос об уместности применения отдельных общенаучных и частнонаучных методов в практике проведения лингвистической экспертизы, анализируются недостатки, имеющие место при формулировании системы применяемых методов в экспертном заключении (неоправданная глобальность, неопределенность, недостаточная информативность, невозможность воспроизведения другими исследователями, многочисленность). Уточняется содержание и процедура применения традиционных лингвистических методов: словарного анализа, синонимических преобразований, экспликации, реферирования, анализа речевых актов и др. Материал статьи актуален не только для подготовки экспертного заключения, но и для научно-исследовательской практики лингвистов в целом, для подготовки будущих специалистов-филологов в вузах, повышения теоретического уровня квалификационных работ студентов и аспирантов.

Ключевые слова: прикладная лингвистика, лингвистическая экспертиза, метод исследования, словарный анализ, синонимическое преобразование, экспликация, реферирование, теория речевых актов.

Цитирование. Баранов А. Н. Лингвистика в лингвистической экспертизе (метод и истина) // Вестник Волгоградского государственного университета. Серия 2, Языкознание. -2017. - Т. 16, № 2. - С. 18-27. - DOI: https://doi.org/10.15688/jvolsu2.2017.2.2.

\section{1. Метод - объективное в необъективном}

Странно говорить о лингвистике в сфеpe, названной лингвистической. Между тем резон в такой постановке вопроса не просто есть, а он весьма велик, значителен и становится решающим для существования «лингвистической экспертизы» как институционального направления и для онтологизации научного дискурса соответствующего типа ${ }^{2}$. Строго говоря, название данной статьи должно было бы звучать как «прикладная лингвистика в лингвистической экспертизе», поскольку лингвистическая экспертиза относится к ведению именно прикладной лингвистики и является ее разделом [Баранов, 2004; 2007], но для вящей значительности опустим это обидное определение, в какой-то мере унижающее деловую репутацию лингвистической экспертизы. Кроме того (и по сути дела), исследования в области лингвистической экспертизы существенно влияют на лингвистическую теорию (или, по крайней мере, в идеале должны влиять), а прикладная лингвистика как служанка и лингвистической теории, и ее приложений лишь фиксирует соответствующие результаты - изменения в метаязыке описания явлений языка и речи.

Роль лингвистики в лингвистической экспертизе требует специального рассмотрения, как минимум по двум причинам: во-первых, потому, что, вопреки здравому смыслу, новые подходы в системе подготовки соответствующих специалистов полностью игнорируют собственно лингвистический характер знаний лингвистов-экспертов, сводя его к юридической образованщине, и, во-вторых, потому, что падение уровня лингвистических знаний, а также прагматические факторы, обсуждать которые в научном журнале не пристало, приводят к падению научного уровня экспертных исследований ${ }^{3}$, превращая их в тексты жанра «чего изволите». Нет нужды говорить, что это пагубная тенденция развития лингвистической экспертизы, которая в ближайшей перспективе определенно приведет к исчезновению обсуждаемого направления как общественно полезной и востребованной деятельности. Действительно, кому нужны исследования, основанные на уверенности экспертов в собственной власти над словами ${ }^{4}$.

Лингвистическая экспертиза - не как научное направление, а как продукт и результат деятельности лингвиста-эксперта - представляет собой бинарный феномен: это специальным образом оформленный результат лингвистического исследования языковых данных (письменного текста, звучащей речи, транскрипта диалога, словесного или комбинированного товарного знака, вербальной составляющей изображения и т. д.), выполнен- 
ный по заказу для использования за пределами лингвистики как науки и социального института. Иными словами, лингвистическая экспертиза - это особый жанр текста, в основе которого лежит научное исследование.

Выход лингвистических экспертиз за пределы лингвистики - вовне - фактически уничтожает контроль теории над практикой применения лингвистических знаний. Результат понятен - от откровенной некомпетентности до обоснования лингвистических приемов выявления лжи в тексте. Попытки борьбы с этими явлениями амбивалентны, поскольку используются как теми, кто честно пытается изменить ситуацию к лучшему, так и теми, кто скрывает свою некомпетентность за нагромождением терминов в духе «культа карго» 5 .

Одна из попыток такого рода - обоснование методических принципов проведения экспертных исследований. Экспертиза институционально предполагает ясное указание на те методы, которые используются экспертом. В идеале привлечение тех же методов должно позволить независимому специалисту проверить полученные результаты. Возможность проверки результата в независимом исследовании является необходимым условием объективности исследования, а с объективностью в гуманитарных науках, как известно, дело обстоит не очень хорошо ${ }^{6}$. Сходная проблема возникает при защите разнообразных квалификационных работ, которые по регламенту ВАК также должны содержать перечисление используемых методов.

Мысль о значимости научных методов не нова. Еще Ф. Ницше, характеризуя состояние науки в свою эпоху, писал о том, что XIX в. «характеризует не победа науки, а победа научного метода над наукой» [Nietzsche, 1906, S. 466] ${ }^{7}$. Современный пример превращения метода в научную дисциплину - трансформационная порождающая грамматика, основанная на методе синтаксических трансформаций.

Методику проведения научной работы можно определить в первом приближении как в той или иной степени алгоритмизированное описание действий специалиста при изучении объекта для ответа на вопросы некоторого фиксированного (регламентиро- ванного) типа. За каждой методикой стоят методы исследования - наиболее общие принципы проведения анализа материала в некоторой научной дисциплине применительно к конкретному объекту, основанные на теоретических представлениях об этом объекте. Так, за методикой анализа текста в рамках дел по экстремизму, предложенной коллективом авторов [Кукушкина, Сафонова, Секераж, 2014], стоят методы лингвистической семантики, методы, сформулированные в теории речевых актов, а также в ряде разделов психологии. Соответствующие научные методы обоснованы в теоретических разделах научных дисциплин, а методики исследования представляют собой оптимизацию (то есть некоторое упрощение) научных методов применительно к конкретной задаче и конкретно выбранному типизированному объекту. Приведенные определения не идеальны, но достаточны для рассмотрения типичных проблем, возникающих в связи с применением методов в лингвистической экспертизе текста ${ }^{8}$.

Такова - вкратце - теоретическая схема, позволяющая соотнести научные методы и методики анализа в лингвистической экспертизе текста. Реальная практика лингвистической экспертизы показывает чрезвычайно богатую палитру методов и отчасти связанных с ними методик, которые используют в своих исследованиях лингвисты-эксперты. Весьма разнообразен набор методов и методик, которые указываются в экспертизах, но реально не используются. Иными словами, часто (может быть, даже по большей части) отсылка к методам и методикам носит чисто декларативный характер: требуется - укажем. Гуманитарное знание (за очень небольшими исключениями) не озабочивается доказательностью и объективностью.

Между тем в большинстве случаев лингвисты в экспертных исследованиях используют тривиальный набор методик, в котором стесняются признаться. Покажем, что стесняться нечего, если эти тривиальные и простые методы научного анализа речевого материала дают необходимые результаты, позволяют провести качественное исследование, объективизировать его результаты и достигнуть необходимой полноты и точности. 


\section{Ogólna teoria wszystkiego}

Жанр лингвистической экспертизы противоречив. С одной стороны, в основе лингвистической экспертизы лежит научное исследование, а с другой - участники процесса (стороны и суд) претендуют на знание русского языка, поскольку по большей части являются его носителями. Объяснять различие во владении языком и научном знании - типичная ошибка начинающих экспертов. Если стороны убеждены, что знают и понимают обсуждаемый спорный текст не хуже эксперта, следует эту позицию безропотно принимать, строя свою аргументацию в рамках этой данности. Иначе лингвисту-эксперту сообщат, что тоже знакомы со словарем Оже́гова, а уж пишутто совсем почти без ошибок. В этом смысле эксперты в области баллистики, химии, почерковеды и др. специалисты естественных или почти естественных наук находятся в более выигрышном положении, чем лингвист.

Таким образом, жанр лингвистической экспертизы требует адаптации проведенного научного исследования таким образом, чтобы аргументация лингвиста-эксперта была понятна окружающим, а ссылки на литературу не пугали неофитов, коими по большей части и являются участники судебного процесса ${ }^{9}$. С другой стороны, текст экспертизы (или заключения специалиста - в данном случае неважно) используется сторонами как аргумент в судебном споре. Может быть, по этой причине некоторые специалисты-лингвисты, стремясь максимально усилить свою аргументацию с риторической точки зрения, указывают на использование методов анализа и синтеза ${ }^{10}$. Эти методы действительно универсальны и даже глобальны, поскольку используются не только ученым людом, но и простыми смертными, даже если последние не понимают, сколь научно они проводят свою жизнь. Таким образом, ссылка на использование анализа и / или синтеза ничего не дает в смысле возможности воспроизведения результата исследования и не способствует его объективности. С тем же успехом можно писать, что текст экспертизы создан на русском языке ${ }^{11}$. Сходен по глобальности с указанными методами метод сопоставления или сравнения, хотя его упоминание в эксперти- зах по плагиату, а также по некоторым видам товарных знаков не лишено смысла.

К глобалистам можно отнести и тех, кто практикует методы языкознания, лингвистические методы, методы фонетики, грамматики, литературоведения, логикосемантический анализ, контекстный анализ и т. П. Понятно, что и методов языкознания, и лингвистических методов и пр. много. Тем самым ссылки указанного типа неинформативны, хотя, может быть, и не столь бессмысленны, как указание на методы анализа и синтеза.

Всеобщность метода сродни огульности (зафиксированной в польском варианте словосочетания «общая теория всего»), а дефакто - произвольности и неопределенности инструмента, которым пользуется лингвистэксперт.

\section{3. «Обновленцы»}

\section{от современной вузовской науки}

Как известно, обновленцы, обессмерченные в гениальном творении Ильфа и Петрова «Двенадцать стульев», - это сторонники модернизации православия, пытавшиеся после февральской революции осовременить церковное управление и внести новое содержание в обрядность. Модернизированное осмысление уже существующих методов характерно для многих лингвистов-экспертов, обращающихся в своей работе к контент-анализу. Контент-анализ как метод упоминается довольно часто, причем в смысле «анализа содержания». Действительно, английское слово content используется в значении «содержание, суть, смысл, сущность». Между тем словосочетание контент-анализ в мировой науке закрепилось за совершенно конкретным методом исследования. Как известно, контентанализ - это метод изучения значительных по объему текстовых данных, цель которого заключается в том, чтобы по внешним - количественным - характеристикам текста на уровне слов и словосочетаний сделать правдоподобные предположения о его плане содержания и, как следствие, сделать выводы об особенностях мышления и сознания автора текста его намерениях, установках, желаниях, ценностных ориентациях и т. д. Первые опыты ис- 
пользования количественных методов, близких к контент-аналитическим, относятся к концу XIX века. Именно тогда в США были проведены первые исследования тематической структуры газет, которые позволили выявить предпочтения читательской аудитории. В последующем данный метод развивался и широко использовался в социологии ${ }^{12}$.

Иногда в лингвистической экспертизе действительно требуются контент-аналитические методики. Например, исследование тональности (оценочных характеристик) текстов значительного объема следует проводить с использованием принципов контент-анализа. Выявление пропагандистских кампаний также естественно осуществлять на основе методов контент-анализа. Подчеркнем, что во всех этих случаях объектом исследования является статистически достоверная (репрезентативная с точки зрения поставленной задачи) выборка текстов - от сотен тысяч до миллионов словоупотреблений. Квалификация семантического анализа (в любом его варианте - в духе семантических примитивов А. Вежбицкой, на языке толкований московской семантической школы, в порождающей семантике и пр.) как «контент-анализа» некорректна, ошибочна и просто непрофессиональна.

К этому же типу ошибок следует отнести постоянные ссылки в лингвистических экспертизах на популярный метод компонентного анализа. Как известно, данный метод был разработан в структурной лингвистике в середине XX в. для описания семантики системно организованных семантических полей слов - типа терминов родства. У. Лаундсбери и Ф. Гудинаф использовали его при описании терминов родства языков американских индейцев. Суть этого метода состоит в выявлении семантических признаков, различающих значения слов, входящих в одно семантическое поле. Так, признаки 'поколение: старшее младшее', 'пол: мужской - женский' позволяют разграничить в семантическом поле родства слова отеи, мать, сын, дочь, которые будут описаны как включающие или исключающие соответствующие значения указанных признаков ${ }^{13}$. В подавляющем большинстве случаев лингвисту-эксперту такой метод не нужен и реально он не используется: термины родства и аналогичные структурирован- ные группы слов весьма редко оказываются в центре внимания лингвистической экспертизы. Что касается выявления сем в значении слов (как интегральных, так и дифференциальных), то для этого используются существующие методы семантического анализа в частности, метод толкования, словарный метод, метод синонимических преобразований и пр. (см. ниже).

Приходится сталкиваться и с другими «методами» исследования - как с существующими, но не используемыми, так и с очевидными фейками. Весьма популярен концептуальный анализ, реально сводимый к семантическому. Под концептуальным анализом разные ученые понимают совершенно разные сущности. Так, часто концептуальный анализ связывается с исследованием различий в понимании тех или иных абстрактных концептов - свободы, равенства, истины, справедливости, времени, пространства и пр. По большей части это довольно сложные исследовательские конструкты, носящие отчетливые индивидуальные черты автора - cp. известную книгу Ю.С. Степанова о константах русской культуры [Степанов, 1997]. Концептуальный анализ как в изводе Ю.С. Степанова, так и в других вариантах практически не воспроизводим другим исследователем, поскольку представляет собой научную публицистику - часто интересную, но малодоказательную. Невозможность воспроизведения данного метода по достаточно простым правилам делает его неприменимым в рамках лингвистической экспертизы текста, в основе которой всегда должен лежать принцип «лучше меньше, да лучше», то есть лучше выявить меньше, но объективно и точно, чем сообщить что-то интересное, но совершенно недоказательное.

К этой же группе ММ следует отнести концептуально-аналитический метод, метод семантической реконструкции, коммуникативный анализ, прагматический анализ, коммуникативно-прагматический анализ и некоторые другие.

\section{4. Методы экспертного анализа: реальность}

Типы лингвистических экспертиз весьма разнообразны. По этой причине универ- 
сальных методов исследования в лингвистической экспертизе текста априори не существует - как не существует универсальных методов в прикладной лингвистике в целом. Действительно, методы анализа речевого сигнала, скорее, заимствуются из сферы акустики, а почерковедческие экспертизы основываются на алгоритмизованных процедурах, описываемых языком математики. Что касается лингвистической экспертизы текста, то трудно будет найти экспертизу, в которой отсутствовали бы методы, основанные на синонимических преобразованиях исследуемого текста. Собственно, синонимические преобразования - важнейшее условие функционирования естественного языка ${ }^{14}$. Синонимическими преобразованиями в первом приближении можно назвать такую модификацию исходного текста (в широком понимании), при которой одни аспекты его семантики сохраняются, приобретая более эксплицитную форму, а другие - могут редуцироваться вплоть до полной элиминации (исчезновения). При синонимических преобразованиях возможна такая ситуация, когда весь объектный текст может подвергаться экспликации, то есть таким синонимическим преобразованиям, когда весь смысл (или его значительная часть) представляется в более эксплицитном (ясном, очевидном) виде.

Эксплицироваться на семантическом метаязыке могут и элементы формы. Так, экспертизы в области языка рекламы часто связаны с повышением эффективности рекламных сообщений. Важнейшей проблемой здесь оказывается взаимодействие собственно текста и изображения (рисунка, фотографии, графика, схемы). Дело в том, что даже гарнитура (тип шрифта, который используется для изображения букв) несет в себе определенную семантику. Например, елизаветинская гарнитура, напоминающая один из шрифтов времен Елизаветы Петровны, для которого при довольно мелком очке, то есть внутреннем пространстве в буквах типа «о», «р», «д», характерно усложненное начертание ряда букв с удлиненными выносными элементами и засечками, связывается с академическим научным стилем, с «классическим» гуманитарным текстом. Готический шрифт тоже имеет свой семантический «ореол», ассоции- руясь со средними веками. Взаимодействие «изобразительной» семантики и вербальной, языковой семантики устроено подчас очень прихотливым образом. Странно было бы видеть, например, книжку юмористических рассказов, выполненных готической гарнитурой. Не менее странно выглядела бы общефедеральная газета, набранная елизаветинской гарнитурой. С другой стороны, академические издания классических текстов с пространными научными комментариями могут использовать шрифты, напоминающие елизаветинскую гарнитуру. Правильное сочетание формы и содержания является предпосылкой для успешного понимания. Во всех этих случаях семантический ореол шрифта описывается вербально, что связывает синонимическими отношениями форму с ореольной семантикой (гарнитуру, шрифт) и вербальное описание этой семантики, разумеется, по необходимости приблизительное, но достаточное для экспертных целей.

Типичный случай синонимических преобразований - реферирование - изложение содержания спорного текста в сокращенном виде, когда эксплицируются лишь та часть его содержания, которая существенна с точки зрения поставленных вопросов. Например, анализ текста по 280 и 282 ст. УК РФ предполагает выявление в тексте призывов, наличие противопоставлений, оценок, обобщенных пропозиций, отнесенных к множеству лиц, объединенных по религиозным, национальным, социальным и другим признакам. Именно эти аспекты содержания текста реферируются лингвистом-экспертом в процессе исследования. Реферирование не только позволяет сделать явными те или иные части содержания текста, но и показывает, как эксперт пришел к соответствующим выводам. Реферирование как метод анализа необходимо и в тех случаях, когда объем материала очень значителен. Проверка результата реферирования вполне доступна независимому специалисту, поскольку легко установить, все ли релевантные части содержания выявлены в процессе исследования.

Видом синонимических преобразований является и словарный анализ. Действительно, толкование в толковом словаре - это способ экспликации семантики слова (или фразе- 
ологизма - для фразеологического словаря). Словарный анализ доступен и легко проверяем, поскольку известные словари общедоступны в печатном виде, а также на разнообразных интернет-сайтах (см., например, slovar.ru, gramota.ru и др.). Словарный анализ необходим в самых разнообразных типах экспертиз. Так, в рамках дел о защите чести, достоинства и деловой репутации (ГК РФ, ст. 152) определяется наличие негативной информации о физическом или юридическом лице. В этом случае обращение к словарной статье словаря оказывается аргументом в пользу наличия такой информации. Ср. во фразе: одним из основных направлений деятельности «бригады Абдулльр» является поставка в Московскую область наркотиков из Таджикистана и Азербайджана слово бригада используется в значении 'воровская группировка; банда, криминальная структура' [Мокиенко, Никитина, 2001]. Соответственно, Абдулла квалифицируется в данном случае как лидер воровской группировки, банды, криминальной структуры, что с очевидностью является негативной информацией.

Синонимические преобразования словарного типа широко используются и в экспертизах по товарным знакам. Например, название товарного знака не может быть описательным, то есть указывать на место производства товара или услуги, а также описывать этот товар или слугу. То есть связь между названием товара или услуги и их содержанием должна быть произвольной, или, как говорят в патентоведении, «фантазийной». Так, словесное обозначение ОПЕРЕТТА является описательным в отношении услуг театра оперетты и фантазийным в отношении товара «духи». Установление смысловой связи между словесным товарным знаком ОПЕРЕТТА (его внутренней формой) и театральными услугами также осуществляется в форме синонимических преобразований: слово оперетта как обозначение вида музыкально-драматического искусства и произведения указанного типа связано по смыслу с театрами, в которых осуществляются постановки оперетт. Таким образом, вывод эксперта-лингвиста по словесным знакам может носить вполне формальный характер, легко воспроизводимый другим специалистом.
При выявлении коммуникативной направленности высказывания широко используется концептуальный аппарат теории речевых актов. Так, при определении призывов, побуждений, обещаний, реплик с семантикой отказа, несогласия или, наоборот, согласия, провокации необходимо учитывать условия успешности соответствующих речевых актов. Многие из указанных речевых актов описаны в классических работах Дж. Остина и Дж.Р. Серля, а многое исследовано в существующей литературе по лингвистической семантике и лингвистической экспертизе текста ${ }^{15}$. Использование инструментария теории речевых актов дает возможность не только правильно квалифицировать коммуникативную направленность анализируемого высказывания (речевого акта), но и проверить себя, соотнеся анализируемое выражение с соответствующим набором условий успешности, характеризующим речевой акт.

Исследование диалога (например, по делам о взятках и вымогательстве) требует учета взаимодействия речевых актов между собой (наличия или отсутствия иллокутивного вынуждения между речевыми актами [Баранов, Крейдлин, 1992]), определения активности участников при обсуждении той или иной темы [Баранов, 2014]. Данные методы также сводимы к синонимическим преобразованиям, относящимся к специфическим слоям плана содержания высказывания и текста.

Лингвистическая экспертиза в области товарных знаков занимается, в частности, тем, что исследует произвольность обозначения товара или услуги.

Разумеется, существуют и другие методы научного исследования, используемые в лингвистике и вполне применимые в лингвистической экспертизе текста. Рассмотренные ММ можно считать наиболее распространенными в практике лингвистической экспертизы.

$$
* * *
$$

Резюмируя (i.e. реализуя один из типов синонимических преобразований), можно привести известные слова Романа Якобсона, писавшего, что «наука о языке не может интерпретировать ни одного лингвистического явления без перевода его знаков в другие знаки той 
же системы или в знаки другой системы» [Якобсон, 1978, с. 16]. Для нас наиболее существенна первая часть данной сентенции - синонимические преобразования предполагают перевод объекта изучения в знаки той же системы, то есть в описание изучаемого на том же языке. В этом смысле деятельность лингвиста-эксперта ничем не отличается от деятельности лингвиста-исследователя.

\section{ПРИМЕЧАНИЯ}

1 Данная статья является расширенной и уточненной версией доклада автора «Методы и методики лингвистической экспертизы» на IV Международной научно-практической конференции «Язык, Право, Общество», проходившей в г. Пенза (Пензенский государственный университет) в октябре 2016 года.

2 Это столь же уместно, как рассуждать о золоте в современных золотых украшениях, о мясе в мясных колбасах, о молочных жирах в молоке и твороге, о сыре в сырных изделиях и пр. - читатель легко продолжит этот немудреный печальный ряд.

3 Здесь и далее, поскольку мы не в суде, не будем делать различий между юридическими тонкостями разграничения лингвистической экспертизы и заключения специалиста, называя далее все эти продукты мысли лингвистической экспертизой.

4 «Когда я беру слово, оно означает то, что я хочу, не больше и не меньше [Кэрролл, 1978, с. 176].

5 В основе культов карго лежит представление туземцев Меланезии о том, что товары западной цивилизации созданы духами предков, которые посылают их меланезийцам. Европейцы обманным путем присвоили эти предметы. Ритуалы культов карго повторяют некоторые особенности поведения белых людей, принимающих полезные грузы, перевозимые самолетами и кораблями. Цель в том, чтобы добиться того же результата - прибытия самолета с едой и одеждой и пр. [Дэвидсон, 1975, с. 229-230].

${ }^{6} \mathrm{CM}$. обсуждение соответствующих проблем в известном сборнике советских времен [Гипотеза..., 1980].

7 На это обращает внимание В.А. Звегинцев в своей книге «Теоретическая и прикладная лингвистика» [Звегинцев, 1967, с. 19]. В современном переводе: «Не победа науки является отличительной чертой нашего XIX века, но победа научного метода над наукой» [Ницше, 2005, с. 275].

8 Далее в основном речь идет о методах, поскольку методики лингвистической экспертизы малочисленны и малодоступны, а часто откровенно безграмотны.
9 А.С. Политковская в свое время выражала недоумение относительно ссылки на Бл. Августина в ответе на вопрос о наличии приемов скрытого речевого воздействия в спорном тексте по делу «Полсинаута». Я высокомерно отверг претензию, а сейчас сознаю, что такие ссылки, во-первых, неуместны в рамках жанра лингвистической экспертизы, а во-вторых, выставляют эксперта «недоумком», случайно выпавшим из башни из слоновой кости.

10 Здесь и далее конкретные экспертизы и заключения не указываются, чтобы не обижать людей. Прошу поверить на слово, что все приводимые названия и типы методов (а также и методик) взяты из реально существующих источников.

11 Впрочем, такое примечание вполне может оказаться релевантным для экспертных исследований, выполняемых, например, для судебных органов Казахстана или Киргизии.

12 Отсылаю читателя к известным работам в области контент-анализа: [Пеше, 1999; Lasswell, 1965]. См. также изложение основ контент-аналитического подхода в: [Баранов, 2001].

13 По компонентному анализу существует огромное количество литературы. См., например: [Nida, 1975]. Из отечественной литературы можно рекомендовать публикацию: [Гулыга, Шендельс, 1976]. В этой статье компонентный анализ распространяется даже на предложения - впрочем, лучше этого не делать.

14 Известная книга Ю.Д. Апресяна «Лексическая семантика» [Апресян, 1974] посвящена именно синонимическим преобразованиям и имеет подзаголовок: «синонимические средства языка».

15 Исследование видов призывов см. в: [Баранов, 2007].

\section{СПИСОК ЛИТЕРАТУРЫ}

Апресян, Ю. Д. Лексическая семантика: синонимические средства языка / Ю. Д. Апресян. М. : Наука, 1974. - 368 с.

Баранов, А. Н. Активность участника коммуникации: методы лингвистического анализа / А. Н. Баранов // Компьютерная лингвистика и интеллектуальные технологии : по материалам ежегод. Междунар. конф. «Диалог» (Бекасово, 4-8 июня 2014 г.). - М. : Изд-во РГГУ, 2014. - Вып. 13 (20).- С. 43-52.

Баранов, А. Н. Введение в прикладную лингвистику / А. Н. Баранов. - М. : Эдиториал УРСС, 2001. $-360 \mathrm{c}$.

Баранов, А. Н. Лингвистическая экспертиза текста / А. Н. Баранов. - М. : Флинта, 2007. - 592 с.

Баранов, А. Н. Теория лингвистических экспертиз как направление прикладной лингвистики / А. Н. Баранов // Компьютерная лингвистика и 
интеллектуальные технологии : по материалам ежегод. Междунар. конф. «Диалог» («Верхневолжский», 2-7 июня 2004 г.). - М. : Наука, 2004. C. 27-31.

Баранов, А. Н. Языковое взаимодействие в диалоге и понятие иллокутивного вынуждения / А. Н. Баранов, Г. Е. Крейдлин // Вопросы языкознания. 1992. -№ 2. - С. 84-99.

Гипотеза в современной лингвистике / отв. ред. Ю. С. Степанов. - М. : Наука, 1980. - 384 с.

Гулыга, Е. В. О компонентном анализе значимых единиц языка / Е. В. Гулыга, Е. И. Шендельс // Принципы и методы семантических исследований / редкол.: В. Н. Ярцева (отв. ред.). - М. : Высшая школа, 1976. - С. 73-86.

Дэвидсон, Б. Африканцы. Введение в историю культуры / Б. Дэвидсон. - М. : Наука, 1975. $280 \mathrm{c}$.

Звегинцев, В. А. Теоретическая и прикладная лингвистика / В. А. Звегинцев. - М. : Просвещение, 1967. $-338 \mathrm{c}$.

Кукушкина, О. В. Методика проведения судебной психолого-лингвистической экспертизы материалов по делам, связанным с противодействием экстремизму и терроризму / О. В. Кукушкина, Ю. А. Сафонова, Т. Н. Секераж. - М. : ФБУ РФЦСЭ при Минюсте России, 2014. - 98 с.

Кэрролл, Л. Приключения Алисы в Стране чудес; Сквозь Зеркало и Что там увидела Алиса, или Алиса в Зазеркалье / Л. Кэрролл ; отв. ред. Б. И. Пуришев. - М. : Наука, 1978. - 359 с.

Мокиенко, В. М. Большой словарь русского жаргона / В. М. Мокиенко, Т. Г. Никитина. - СПб. : Норинт, 2001. - 717 c.

Ницше, Ф. Воля к власти / Ф. Ницше. - М. : Культурная революция, 2005. - 880 с.

Пеше, М. Контент-анализ и теория дискурса / М. Пеше // Квадратура смысла: французская школа анализа дискурса / под ред. П. Серио. - М. : Прогресс, 1999. - С. 302-336.

Степанов, Ю. С. Константы: словарь русской культуры / Ю. С. Степанов. - М. : Языки русской культуры, 1997. - 824 с.

Якобсон, Р. О. О лингвистических аспектах перевода / Р. О. Якобсон // Вопросы теории перевода в зарубежной лингвистике. - М. : [б. и.], 1978. C. 16-24.

Lasswell, H. D. Language of politics. Studies in quantitative semantics / H. D. Lasswell. - Cambridge (Mass) : M.I.T. Press, 1965. -398 p.

Nida, E. A. Componential Analysis of Meaning

/ E. A. Nida. - The Hague : Mouton, 1975. - 243 p.

Nietzsche, F. Der Wille zur Macht / F. Nietzsche. Leipzig: Naumann Verlag, 1906. - 538 S.

\section{REFERENCES}

Apresyan Yu.D. Leksicheskaya semantika: Sinonimicheskie sredstva yazyka [Lexical Semantics: Synonymic Means of the Language]. Moscow, Nauka Publ., 1974. 368 p.

Baranov A.N. Aktivnost uchastnika kommunikatsii: metody lingvisticheskogo analiza [The Communicants Activity: Methods of Linguistic Analysis]. Kompyuternaya lingvistika $i$ intellektualnye tekhnologii: po materialam ezhegod. Mezhdunar. konf. "Dialog» (Bekasovo, 48 iyunya 2014 g.) [Computation Linguistics and Intellectual Technologies: Based on Materials of Dialogue Annual International Conference (Bekasovo, June 4-8, 2014)]. Moscow, Izd-vo RGGU, 2014, iss. 13 (20), pp. 43-52.

Baranov A.N. Vvedenie v prikladnuyu lingvistiku [Introduction to Applied Linguistics]. Moscow, Editorial URSS Publ., 2001.360 p.

Baranov A.N. Lingvisticheskaya ekspertiza teksta [Linguistic Investigation of the Text]. Moscow, Flinta Publ., 2007. 592 p.

Baranov A.N. Teoriya lingvisticheskikh ekspertiz kak napravlenie prikladnoy lingvistiki [The Theory of Linguistic Investigations as a Branch of Applied Linguistics]. Kompyuternaya lingvistika $i$ intellektualnye tekhnologii: po materialam ezhegod. Mezhdunar. konf. "Dialog» ("Verkhnevolzhskiy», 27 iyunya 2004 g.) [Computation Linguistics and Intellectual Technologies: Based on Materials of Dialogue Annual International Conference (Verhnevolzhsky, June 2-7, 2004)]. Moscow, Nauka Publ., 2004, pp. 27-31.

Baranov A.N., Kreydlin G.E. Yazykovoe vzaimodeystvie $\mathrm{v}$ dialoge $\mathrm{i}$ ponyatie illokutivnogo vynuzhdeniya [Language Interaction in the Dialogue and the Notion of Illocutionary Compulsion]. Voprosy yazykoznaniya, 1992, no. 2, pp. 84-99.

Stepanov Yu.S., ed. Gipoteza v sovremennoy lingvistike [Hypothesis in Modern Linguistics]. Moscow, Nauka Publ., 1980. 384 p.

Gulyga E.V., Shendels E.I. O komponentnom analize znachimykh edinits yazyka [On the Componential Analysis of Meaningful Linguistic Units]. Yartseva V.N., ed. Printsipy $i$ metody semanticheskikh issledovaniy [Principles and Methods of Semantic Research]. Moscow, Vysshaya shkola Publ., 1976, pp. 73-86.

Devidson B. Afrikantsy. Vvedenie v istoriyu kultury [Africans. Introduction to the History of Culture]. Moscow, Nauka Publ., 1975. 280 p.

Zvegintsev V.A. Teoreticheskaya i prikladnaya lingvistika [Theoretical and Applied Linguistics]. Moscow, Prosveshchenie Publ., 1967. 338 p. 
Kukushkina O.V., Safonova Yu.A., Sekerazh T.N. Metodika provedeniya sudebnoy psikhologolingvisticheskoy ekspertizy materialov po delam, svyazannym s protivodeystviem ekstremizmu $i$ terrorizmu [The Methodology of Forensic PsychoLinguistic Examination of Cases, Related to Counteraction to Extremism and Terrorism]. Moscow, FBU RFTsSE pri Minyuste Rossii, 2014. 98 p.

Carroll L. Priklyucheniya Alisy v Strane chudes; Skvoz Zerkalo i Chto tam uvidela Alisa, ili Alisa v Zazerkalye [Alices Adventures in Wonderland; Through the Looking Glass and What Alice Found There]. Moscow, Nauka Publ., 1978. 359 p.

Mokienko V.M., Nikitina T.G. Bolshoy slovar russkogo zhargona [Big Dictionary of Russian Jargon]. Saint Petersburg, Norint Publ., 2001. 717 p.

Nietzsche F. Volya $k$ vlasti [The Will to Power]. Moscow, Kulturnaya revolyutsiya Publ., 2005. 880 p.

Pêcheux M. Kontent-analiz i teoriya diskursa [Content Analysis and the Theory of Discourse].
Serio P., ed. Kvadratura smysla: Frantsuzskaya shkola analiza diskursa [The Quadrature of Meaning: French School of Discourse Analysis]. Moscow, Progress Publ., 1999, pp. 302-336.

Stepanov Yu.S. Konstanty: Slovar russkoy kultury [Constants: Dictionary of Russian Culture]. Moscow, Yazyki russkoy kultury Publ., 1997. 824 p.

Yakobson R.O. O lingvisticheskikh aspektakh perevoda [On Linguistic Aspects of Translation]. Voprosy teorii perevoda $v$ zarubezhnoy lingvistike [Issues of Translation Theory in Foreign Linguistics]. Moscow, 1978, pp. 16-24.

Lasswell H.D. Language of Politics. Studies in Quantitative Semantics. Cambridge (Mass), M.I.T. Press, $1965.398 \mathrm{p}$.

Nida E.A. Componential Analysis of Meaning. The Hague, Mouton, 1975. 243 p.

Nietzsche F. Der Wille zur Macht. Leipzig, Naumann Verlag, 1906. 538 p.

\section{Information About the Author}

Anatoliy N. Baranov, Doctor of Sciences (Philology), Professor, Head of Department of Experimental Lexicography, Russian Language Institute RAS (Vinogradov Institute), Volkhonka St., 18/2, 119019 Moscow, Russian Federation, ruslang@ruslang.ru, Researcher ID: http:// www.researcherid.com/rid/J-7113-2017.

\section{Информация об авторе}

Анатолий Николаевич Баранов, доктор филологических наук, профессор, заведующий отделом экспериментальной лексикографии, Институт русского языка им. В.В. Виноградова РAН, ул. Волхонка, 18/2, 119019 г. Москва, Российская Федерация, ruslang@ruslang.ru, Researcher ID: http://www.researcherid.com/rid/J-7113-2017. 